\title{
A Choline Chloride-Ethylene Glycol Deep Eutectic Solvent Based on Magnetic Polydopamine with Preconcentration and Determination for Sulfonylurea Herbicides in Water Samples
}

\author{
Dan-Dan Wang, ${ }^{a}$ Zhi-Heng Lu, ${ }^{a}$ Mei-Nan O. Yang, ${ }^{a}$ Hao-Ming Guo ${ }^{a}$ and Zhong-Hua Yang ${ }^{\circledR *} * a$ \\ ${ }^{a}$ Department of Plant Protection, College of Plant Science and Technology, \\ Huazhong Agriculture University, 430070 Wuhan, China
}

\begin{abstract}
In this study, a novel deep eutectic solvent (DES) containing choline chloride and ethylene glycol was synthesized, and the magnetic polydopamine (PDA) was modified with this deep eutectic solvent to form $\mathrm{Fe}_{3} \mathrm{O}_{4} @ \mathrm{PDA}-\mathrm{DES}$. Fourier transformed infrared spectroscopy, scanning electron microscopy, and vibrating sample magnetometer were used to characterize the proposed adsorbent. Then, this magnetic material was used as an adsorbent in the magnetic solid phase extraction process for the extraction of four sulfonylurea herbicides in water samples. The main parameters relevant to this method were investigated. Under the optimum conditions, the linearity was obtained by five points in the concentration range of 1.0-200 $\mu \mathrm{g} \mathrm{L}^{-1}$ and with the correlation coefficients $(r) \geq 0.9927$. The enrichment factors were in a range of 495 to 615 and the relative standard deviations were less than $4.3 \%$. The limits of detection varied from 0.0092 to $0.0113 \mu \mathrm{g} \mathrm{L} \mathrm{L}^{-1}$. The recoveries of environmental water samples were 61.9 to $100.1 \%$, and the recoveries of drinking water samples were 71.1-101.9\%. All results highlighted the excellent potential of magnetic solid phase extraction coupled with ultra-high performance liquid chromatography strategy in selective separation and extraction of sulfonylurea herbicides in water samples.
\end{abstract}

Keywords: sulfonylurea herbicides, deep eutectic solvent, choline chloride, magnetic polydopamine, water samples

\section{Introduction}

Sulfonylurea herbicides (SUHs) are one type of herbicides with high herbicidal activity and low toxicity. They are increasingly used for the control of broad-leaved weeds and some other weeds. However, the widespread application of SUHs results in their occurrence in adjacent environmental systems. Therefore, the analysis of SUHs residue is of great importance to environmental protection and human health. Sample pretreatment technique is a significantly vital step in chemical analysis. Presently reported pretreatment techniques for the detection of sulfonylurea herbicides mainly include solid phase extraction (SPE), ${ }^{1-3}$ dispersed solid phase extraction (DSPE), ${ }^{4}$ and molecularly imprinted solid phase extraction (MISPE). ${ }^{5}$ SPE is the most frequently used method in all these sample pretreatment technologies. Miniaturization of separation technology, especially in liquid-phase and solid-phase extraction methods, is

*e-mail: yangzhonghua @ mail.hzau.edu.cn a trend of analytical chemistry, which could improve extraction efficiency, reduce operating costs, and have no environmental pollution. Recently, magnetic solid phase extraction (MSPE) has received increasing attention as a relative neotype of SPE technique based on the use of magnetic or magnetizable adsorbents. ${ }^{6}$ It possesses advantages of high extraction efficient, high enrichment factor, easy and convenient operational process, and can be applied directly in rough samples. ${ }^{7}$ Meanwhile, the magnetic solid phase extraction technique simplifies the sample processing process and saves time. ${ }^{8,9}$

Polydopamine (PDA) is formed by mild oxidative polymerization of dopamine under alkaline condition. PDA is rich in amino and phenolic hydroxyl groups which can easily adhere to different materials. ${ }^{10,11}$ PDA has been widely used in surface modification, ${ }^{12}$ controlled release, ${ }^{13}$ immunoassays ${ }^{14}$ and MSPE process. ${ }^{15-17}$

Deep eutectic solvent (DES), as a novel green solvent with similar physical properties and phase behavior to ionic liquids, ${ }^{18}$ was firstly introduced by Abbot et al. ${ }^{19}$ in 2003. DES has attracted extensive attention because of the advantages 
such as low vapor pressure, wide liquid phase range, easy preparation, low cost, and non-toxicity. ${ }^{20}$ These solvents are usually synthesized by mixing quaternary ammonium salts as hydrogen bond acceptors (HBA) and naturally derived non-charged hydrogen bond donors (HBD). ${ }^{21}$ In particular, as a biodegradable and non-toxic quaternary ammonium salt, choline chloride $(\mathrm{ChCl})$ has become a commonly used hydrogen-bonded donor in DES. ${ }^{22}$ Because of the excellent characteristics, $\mathrm{DES}$ prepared by $\mathrm{ChCl}$ has been used in areas such as organic synthesis, ${ }^{23}$ electro-deposition, ${ }^{24}$ extraction of heavy metal ions, ${ }^{25}$ nano-materials ${ }^{26}$ preparation and separation process. ${ }^{27}$

In the current study, we synthesized a novel DES by mixing choline chloride (HBA) and ethylene glycol (HBD). The obtained DES has both hydrophilic and hydrophobic functional groups, which could enhance its selectivity and adsorption capacity. After a series of synthetic processes, a magnetic polydopamine adsorbent $\left(\mathrm{Fe}_{3} \mathrm{O}_{4} @ \mathrm{PDA}-\mathrm{DES}\right)$ was prepared and applied in MSPE coupled with ultrahigh-performance liquid chromatography (UPLC) for the determination of sulfonylurea herbicide in aqueous samples. The synthesized magnetic material was confirmed systematically through a series of characterization methods. The extraction parameters such as adsorbent dosage, ionic strength, and sample $\mathrm{pH}$ value were optimized.

\section{Experimental}

\section{Chemicals and materials}

All reagents used in the experiments were analytical grade or chromatographic grade. $\mathrm{ChCl}$ and ethylene glycol (EG) were obtained from Shanghai Aladdin BioChem Technology Co. Ltd. (Shanghai, China). Dopamine (DA) was obtained from Tianjin Xiens Biochemical Technology Co., Ltd. (Tianjin, China). Potassium bromide $(\mathrm{KBr}), \mathrm{FeCl}_{3} \cdot 6 \mathrm{H}_{2} \mathrm{O}, \mathrm{FeCl}_{2} \cdot 4 \mathrm{H}_{2} \mathrm{O}, \mathrm{HCl}, \mathrm{NaOH}$, anhydrous ethanol, ammonia and sodium chloride were analytical grades and obtained from Sinopharm Chemical Reagent Co., Ltd. (Shanghai, China). HPLC (high-performance liquid chromatography) grade acetonitrile $(\mathrm{ACN})$ and methanol $(\mathrm{MeOH})$ were provided by Fisher Chemistry Reagent Co. Ltd. (Waltham, USA). Sodium dodecyl sulfate (SDS) was achieved from Xilong Chemistry Co. Ltd. (Shantou, China). Ammonium persulfate (APS) and $N, N$-methylenebisacrylamide (MBAAm) were purchased from Fucheng Chemicals (Tianjin, China). Tetraethyl orthosilicate (TEOS) was obtained from Alfa Aesar (Waltham, USA). High-purity deionized water $(18.2 \mathrm{M} \Omega \mathrm{cm})$ purified by a Milli-Q water purification system (Millipore, Bedford, MA, USA) was used.
Sulfosulfuron, bensulfuron-methyl, pyrazosulfuron-ethyl and halosulfuron-methyl were obtained from the Testing Center of the Shanghai Pesticide Research Institute (Shanghai, China) with purity over $95 \%$. Stock standard solutions of target pesticides were prepared at $1.0 \mathrm{~g} \mathrm{~L}^{-1}$ in methanol. The stock and working standard solutions were stored in dark at $4{ }^{\circ} \mathrm{C}$ until use.

\section{Apparatus and analytical conditions}

The detection process was performed with an ultraperformance liquid chromatography (Nexera X2 Shimadzu, Japan) equipped with an SPD-M30A PDA detector, an LC-30AD quaternary pump system, an SIL-30AC auto sampler, and a CTO-30A thermostatic column compartment. Chromatographic separation of the analyte was carried out on a Waters Acquity UPLC BEH $\mathrm{C}_{18}$ column $(100 \times 2.1 \mathrm{~mm}, 1.7 \mu \mathrm{m})$. The mobile phases were $0.1 \%$ formic acid (solvent $\mathrm{A}$ ) and acetonitrile (solvent B). The analytes were separated with the following gradient program: $0 \mathrm{~min}, 30 \% \mathrm{~B}$; 0-11.0 $\mathrm{min}, 30-60 \% \mathrm{~B}$; 11.0-15.0 min, $60-90 \% \mathrm{~B}$; $15.0-16.0 \mathrm{~min}, 90-30 \% \mathrm{~B}$; $16.0-20 \mathrm{~min}, 30 \% \mathrm{~B}$. The flow rate was set at $0.45 \mathrm{~mL} \mathrm{~min}^{-1}$. The sample injection volume was $20 \mu \mathrm{L}$. Absorbance was monitored at $254 \mathrm{~nm}$ and the column temperature was held constant at $35^{\circ} \mathrm{C}$. Fourier transform-infrared spectrometer (FTIR, Model Nexus 470, Nicolet USA) and KBr were used to identify functional groups of the magnetic microspheres. The morphologies of adsorbent were characterized on a scanning electron microscopy (SEM) instrument (Model 8010, Tian Mei Instrument Co., Ltd., China). The magnetic measurements were conducted using a vibrating sample magnetometer (Model PPMS-9 Squid-VSM, Quantum Design, USA). The magnetic moments were measured under applied magnetic fields varying from -2000 to $+2000 \mathrm{G}$ at $300 \mathrm{~K}$.

\section{Synthesis of magnetic nanocomposite}

\section{Preparation of DES}

Choline chloride and ethylene glycol were accurately weighed at 1:2 $\mathrm{M}$ ratio and combined in a $100 \mathrm{~mL}$ roundbottom flask. Then, the mixture was stirred at $80^{\circ} \mathrm{C}$ for $1 \mathrm{~h}$ until a clear liquid was obtained. After cooling, the DESs were stored at room temperature.

\section{Preparation of $\mathrm{Fe}_{3} \mathrm{O}_{4}$ nanoparticles}

$\mathrm{Fe}_{3} \mathrm{O}_{4}$ nanoparticles were prepared by the wellknown coprecipitation method. ${ }^{28} 5.2 \mathrm{~g} \mathrm{FeCl}_{3} \cdot 6 \mathrm{H}_{2} \mathrm{O}$ and $2.0 \mathrm{~g} \mathrm{FeCl}_{2} \cdot 4 \mathrm{H}_{2} \mathrm{O}$ were dissolved in $160 \mathrm{~mL}$ ultrapure water which was degassed with nitrogen gas to agitate 
the mixture. Then, $30 \mathrm{~mL} \mathrm{NH} \cdot \mathrm{H}_{2} \mathrm{O}$ was added to the solution. The mixture was kept in a magnetic stirrer at $80{ }^{\circ} \mathrm{C}$ for $50 \mathrm{~min}$ with vigorous stirring. Black particles were recovered by an external magnet after washing by ultrapure water. Finally, the mixture was dried in a $60{ }^{\circ} \mathrm{C}$ vacuum oven for $12 \mathrm{~h}$ to achieve the $\mathrm{Fe}_{3} \mathrm{O}_{4}$ nanoparticles.

\section{Preparation of $\mathrm{Fe}_{3} \mathrm{O}_{4} @$ PDA}

$\mathrm{Fe}_{3} \mathrm{O}_{4} @ \mathrm{PDA}$ was prepared according to the reported literature. ${ }^{29}$ The prepared $\mathrm{Fe}_{3} \mathrm{O}_{4}$ nanoparticles $(400 \mathrm{mg})$ were dispersed in $250 \mathrm{~mL}$ Tris buffer solution $(\mathrm{pH}=8.5)$ containing $400 \mathrm{mg}$ dopamine. The mixture was continuously sonicated for $30 \mathrm{~min}$ in water bath and reacted at room temperature for $10 \mathrm{~h}$. Under alkaline condition, $\mathrm{Fe}_{3} \mathrm{O}_{4}$ nanoparticles were introduced into PDA to form $\mathrm{Fe}_{3} \mathrm{O}_{4} @ \mathrm{PDA}$ nanoparticles. $\mathrm{Fe}_{3} \mathrm{O}_{4} @$ PDA nanoparticles were collected by magnet separation and washed with deionized water and ethanol. At last, the nanoparticles were dried in a vacuum oven at $60{ }^{\circ} \mathrm{C}$.

\section{Preparation of $\mathrm{Fe}_{3} \mathrm{O}_{4} @$ PDA-DES}

$\mathrm{Fe}_{3} \mathrm{O}_{4} @ P D A-D E S$ were prepared through a seed

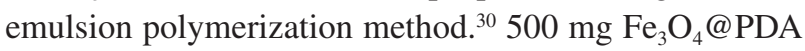
was dispersed into $210 \mathrm{~mL}$ deionized water and $40 \mathrm{~mL}$ ethanol. $50 \mathrm{mg}$ SDS was added into the mixture and stirred at room temperature for $30 \mathrm{~min}$. Then, $5 \mathrm{~mL}$ DES and $200 \mathrm{mg}$ MBAAm were added, followed by continuously bubbling with $\mathrm{N}_{2}$ for $30 \mathrm{~min}$. When the mixture was heated to $65{ }^{\circ} \mathrm{C}, 2.5 \mathrm{~mL}$ APS solution having a concentration of $0.02 \mathrm{~g} \mathrm{~mL}^{-1}$ was added to the dispersion to initiate polymerization. Reaction was continued for $10 \mathrm{~h}$. Finally, the obtained chemical product was collected, washed with deionized water and dried overnight at $40{ }^{\circ} \mathrm{C}$ to get the final magnetic material.

\section{Magnetic solid-phase extraction procedures}

$100 \mathrm{~mL}$ water sample containing $10 \mu \mathrm{g} \mathrm{L}^{-1}$ target analytes was placed in a $250 \mathrm{~mL}$ conical bottle. Then, $1.5 \mathrm{~g}$ of $\mathrm{NaCl}$ was added and the sample $\mathrm{pH}$ was adjusted to 3.0 with $1 \mathrm{M} \mathrm{HCl}$. $200 \mu \mathrm{L}$ methanol were added into $50 \mathrm{mg}$ of magnetic adsorbent and mixed for a while to activate the magnetic adsorbent. Then, the magnetic adsorbent activated was added into the sample. After 5 min of ultrasonic extracting, the sample was allowed to stand for $20 \mathrm{~min}$. The $\mathrm{Fe}_{3} \mathrm{O}_{4} @$ PDA-DES entrapped analytes by weak van der Waals forces and electrostatic interactions, ${ }^{31}$ and then they were separated from the sample solution by an external magnet, and the sample solution became limpid and the upper clear liquid was decanted. Subsequently, the analytes were eluted with
$1.5 \mathrm{~mL}$ of methanol under a vortex mixer. The eluent was collected in a $2 \mathrm{~mL}$ centrifuge tube and blown dry under a nitrogen atmosphere at $40^{\circ} \mathrm{C}$. Finally, $200 \mu \mathrm{L}$ acetonitrile was added for the reconstitution of analytes and filtered through a $0.22 \mu \mathrm{m}$ membrane before analysis by UPLC.

\section{Method validation}

Under the optimum conditions, the proposed MSPE-UPLC method was validated according to the linearity, correlation coefficient, limit of detection (LOD), limit of quantitation (LOQ) and relative standard deviations (RSD). The linearity was obtained by using five points in the concentration range of 1-200 $\mu \mathrm{g} \mathrm{L} \mathrm{L}^{-1}$. The repeatability was expressed as RSDs for three replicate analyses. The LOD was evaluated based on signal-to-noise ratio $(\mathrm{S} / \mathrm{N})$ of 3. The enrichment factor (EF) was the ratio between the concentration of the analytes in the extraction solvent and the concentration of the analytes in the sample. The $\mathrm{EF}$ value was used to evaluate the extraction performance of the MSPE.

\section{Analysis of water samples}

In order to evaluate the applicability of our recommended method, six liquid samples were collected and analyzed. Lake water samples were collected from Nanhu Lake and Yezhihu Lake (Hongshan District, Wuhan). Rice field water sample was obtained from the experimental field of Huazhong Agricultural University. The lake water and the rice water samples were filtered through medium-speed qualitative filter papers. Three drinking water samples were purchased from supermarket of Huazhong Agricultural University, and their brand were Wahaha, Nongfu Spring and Yibao. All water samples were analyzed within $24 \mathrm{~h}$ of collection and stored in dark containers at $4{ }^{\circ} \mathrm{C}$.

\section{Results and Discussion}

\section{Characterization of $\mathrm{Fe}_{3} \mathrm{O}_{4} @$ PDA-DES}

To confirm the structure of $\mathrm{Fe}_{3} \mathrm{O}_{4} @$ PDA-DES, FTIR spectra of $\mathrm{Fe}_{3} \mathrm{O}_{4}, \mathrm{Fe}_{3} \mathrm{O}_{4} @ \mathrm{PDA}$, and $\mathrm{Fe}_{3} \mathrm{O}_{4} @ \mathrm{PDA}-\mathrm{DES}$ were examined and the results were presented in Figure 1. The absorption peaks of DES appearing at 2923 and $2854 \mathrm{~cm}^{-1}$ were belonged to $-\mathrm{CH}_{3}$ and $-\mathrm{CH}_{2}$ groups. The peak intensity of the bending vibration of $-\mathrm{H}$ on the benzene ring of the PDA was located at a wavenumber of about $1506 \mathrm{~cm}^{-1}$. The peak at $1293 \mathrm{~cm}^{-1}$ was from the characteristic absorption of $\mathrm{C}-\mathrm{N}$. The peak at about $586 \mathrm{~cm}^{-1}$ was associated with the stretching vibrations of 
$\mathrm{Fe}-\mathrm{O}$. It can be obviously seen that the synthetic material contains these characteristic peaks. Based on the above results, DES was confirmed to be involved in the synthesis of magnetic polydopamine.

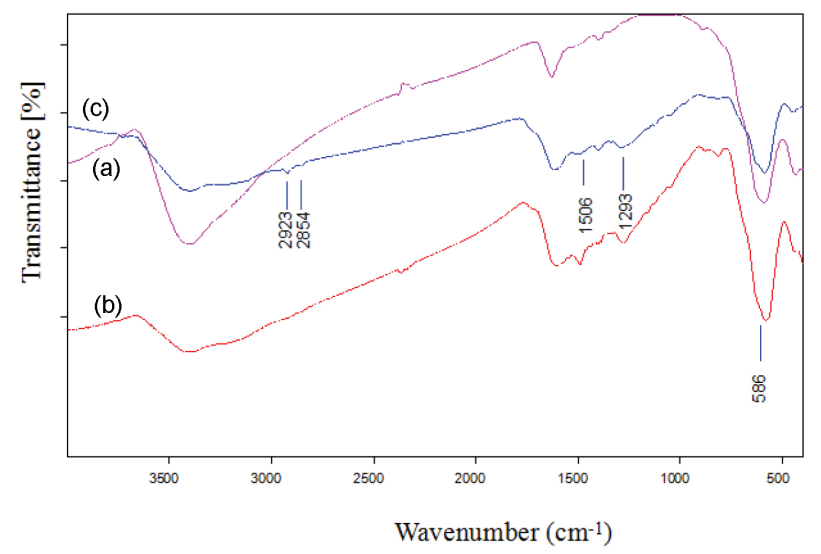

Figure 1. FTIR spectra (KBr) of (a) $\mathrm{Fe}_{3} \mathrm{O}_{4}$; (b) $\mathrm{Fe}_{3} \mathrm{O}_{4} @ \mathrm{PDA}$ and (c) $\mathrm{Fe}_{3} \mathrm{O}_{4} @$ PDA-DES.

The scanning electron microscopy image of $\mathrm{Fe}_{3} \mathrm{O}_{4} @$ PDA-DES was shown in Figure 2. It can be seen that the surface of this magnetic composite material was rough and more irregular which proved that the DES was successfully bonded.

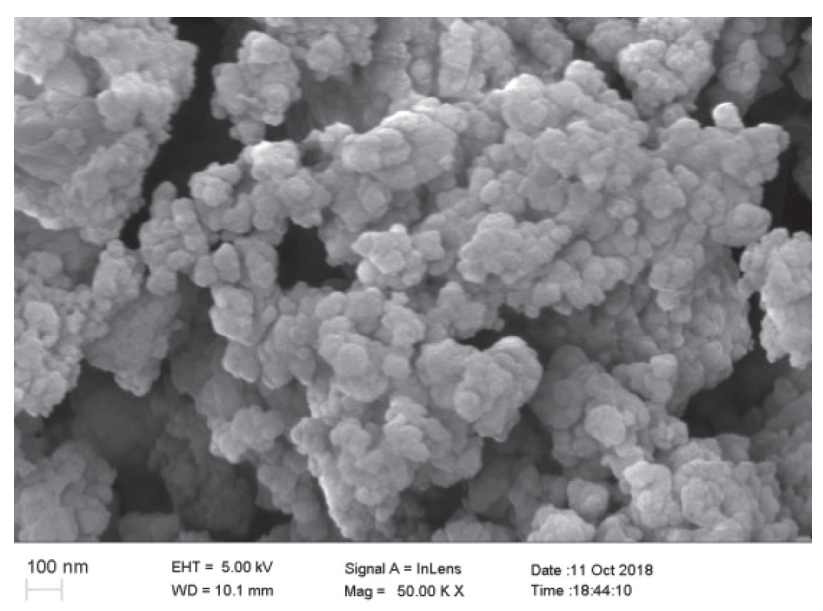

Figure 2. Scanning electron microscopy image of $\mathrm{Fe}_{3} \mathrm{O}_{4} @$ PDA-DES.

Magnetism is a key factor for magnetic materials. Magnetization curves of two materials are listed in Figure 3. The saturation magnetization of $\mathrm{Fe}_{3} \mathrm{O}_{4} @ \mathrm{PDA}$, $\mathrm{Fe}_{3} \mathrm{O}_{4} @$ PDA-DES gradually decreased to 50.9 and $43.2 \mathrm{emu}^{-1}$, respectively. The lessening of saturation magnetization in $\mathrm{Fe}_{3} \mathrm{O}_{4} @$ PDA-DES can be attributed to DES successfully formed on the surface of $\mathrm{Fe}_{3} \mathrm{O}_{4} @$ PDA. The prepared magnetic $\mathrm{Fe}_{3} \mathrm{O}_{4} @$ PDA-DES has sufficient saturation magnetization to make it sensitive to magnetic fields. In addition, the magnetic material was susceptible to external magnetic fields, which resulted in rapid separation during MSPE process.

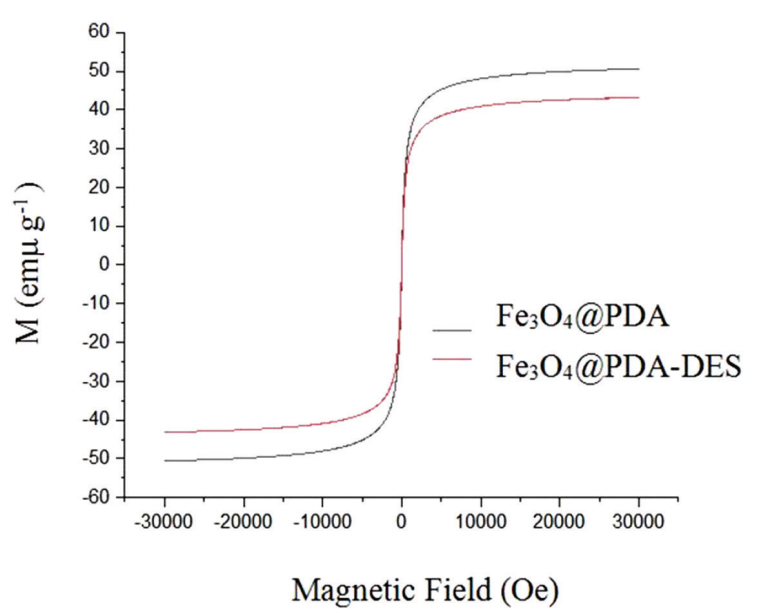

Figure 3. Room temperature magnetization curve of $\mathrm{Fe}_{3} \mathrm{O}_{4} @ \mathrm{PDA}$ and $\mathrm{Fe}_{3} \mathrm{O}_{4} @$ PDA-DES.

\section{Optimization of extraction conditions}

Several experimental variables that affected the extraction efficiencies were investigated, including the extraction time, adsorbent consumption, ionic strength, sample $\mathrm{pH}$ value, and desorption conditions. In all optimization experiments, $10 \mu \mathrm{g} \mathrm{L}{ }^{-1}$ of each analyte was added and the above mentioned variables were modified one at a time while keeping the remaining constants.

\section{Optimization of extraction time}

The effect of extraction time on the performance of MSPE is an important factor. It takes a certain time for the extraction solvent to be dispersed into the aqueous samples. Too short extraction time may result in incomplete extraction, and too long might cause difficulty in elution. Therefore, the effect of extraction time was evaluated over the time range between 5 and $25 \mathrm{~min}$. Analyzing the results shown in Figure 4, 20 min was the proper time for the magnetic material to achieve optimal adsorption of the target compounds. Therefore, $20 \mathrm{~min}$ was chosen as the extraction time for the following studies.

\section{Optimization of adsorbent consumption}

One of the key factor of the adsorption process is the amount of adsorbent, which could affect the adsorption between the adsorbent and the target analytes. A series of adsorbent amount (10-50 $\mathrm{mg}$ ) were weighed to evaluate the effect of adsorbent consumption on the extraction efficiencies. Results shown in Figure 5 indicated that the 


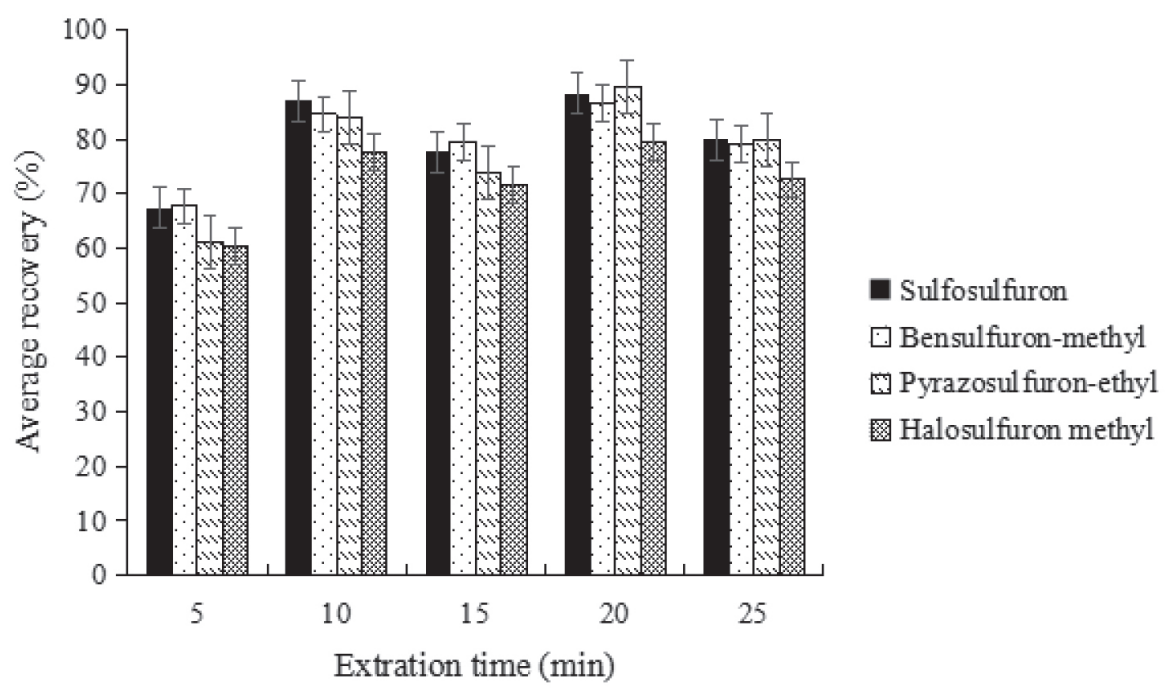

Figure 4. Effect of extraction time on the extraction efficiency of SUHs.

highest extraction efficiencies were achieved when $50 \mathrm{mg}$ adsorbent was added. When the dose of the adsorbent was increased, the herbicides interacted more with the adsorbent. Meanwhile, the recoveries have satisfied the requirements of residue analysis..$^{32}$ Thus, $50 \mathrm{mg}$ of adsorbent dose was selected.

\section{Optimization of ionic strength}

In order to study the effect of the ionic strength on the performance of the presented MSPE procedure, the adding amount of $\mathrm{NaCl}$ varying from 0 to $2 \mathrm{~g}$ were investigated. The results were given in Figure 6, leading to increased efficiencies as the $\mathrm{NaCl}$ content increased from 0 to $1.5 \mathrm{~g}$. When $2 \mathrm{~g}$ of $\mathrm{NaCl}$ was added, the extraction efficiencies of the target analytes decreased. The reason for this maybe excessive salt ions could increase the viscosity of the solution, which made the adsorbent transfer less from the aqueous phase to the surface of the target analytes and reduced the extraction effects. Thus, the subsequent extractions were accomplished with samples containing $1.5 \mathrm{~g} \mathrm{NaCl}$.

\section{Optimization of solution $\mathrm{pH}$ value}

Generally, the $\mathrm{pH}$ value of sample plays a significant role for the adsorption efficiencies. The molecular state of target analytes could be affected by the solution $\mathrm{pH}$ value. In this study, the $\mathrm{pH}$ value was adjusted with $\mathrm{HCl}$ and $\mathrm{NaOH}$ solution and the effect of $\mathrm{pH}$ value was investigated by varying the sample $\mathrm{pH}$ from 3.0 to 7.0. According the obtained data (Figure 7), we can conclude that the extraction efficiencies increased when the $\mathrm{pH}$ value decreased. This can be explained by the fact that

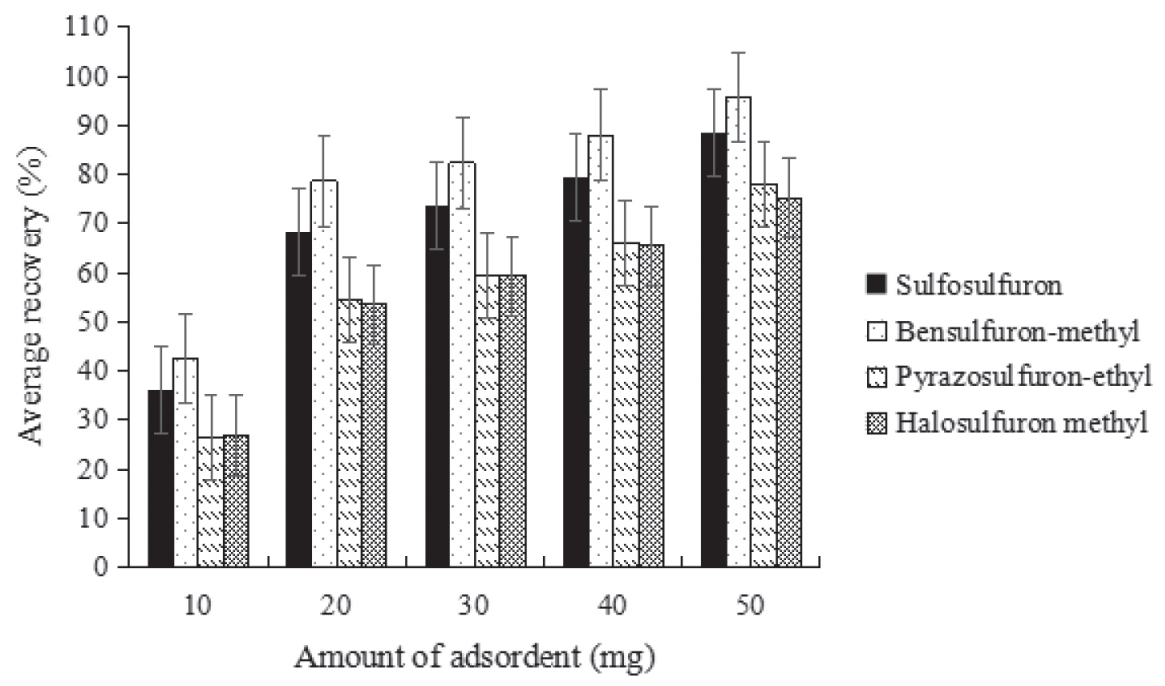

Figure 5. Effect of adsorbent dosage on the extraction efficiency of SUHs. 


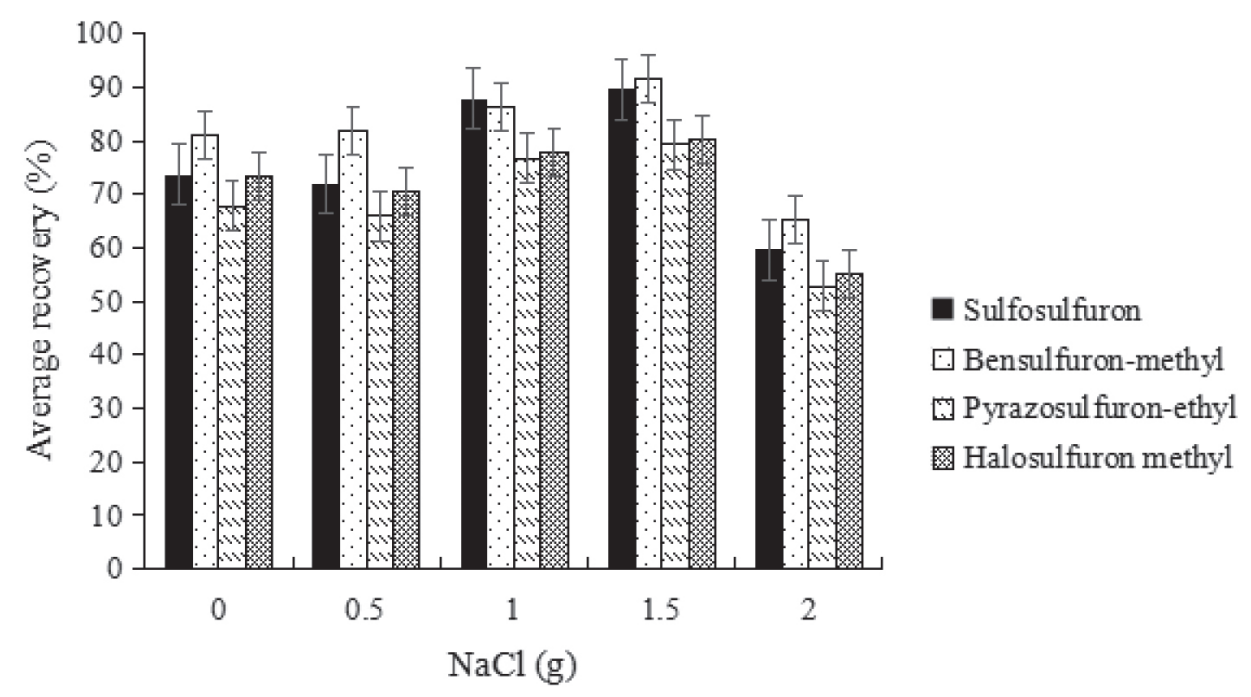

Figure 6. Effect of ionic strength on the extraction efficiency of SUHs.

sulfonylurea herbicides are generally weak acidic with $\mathrm{p} K_{\mathrm{a}}$ values ranging from 3.0 to 5.0. When the $\mathrm{pH}$ value of the sample solution was higher than 5.0, the hydrophobicity of the compounds was reduced, and thus the recoveries rate were reduced. Ultimately, the $\mathrm{pH}$ value of the sample solution was adjusted to 3.0.

\section{Selection of desorption conditions}

Different eluents have different effects on the extraction efficiencies. Suitable elution solvent and volume can fully elute the target analytes, reduce matrix interference and improve extraction efficiencies. The effects of methanol, acetonitrile and acetone on the extraction efficiencies were investigated. As shown in Figure 8 (taking sulfosulfuron as an example), methanol has the best elution ability and the recoveries for SUHs were higher than other elution solvents. Therefore, methanol was chosen as the eluting solvent in the further study.

In order to completely elute the target pesticides on the adsorbent, the volume of elution solvent was studied. From Figure 8 we found that the extraction efficiencies increased when the volume of solvent increased until $1.5 \mathrm{~mL}$. After that, the extraction efficiencies began to decrease. Thus, based on the above results methanol was selected as the extraction solvent, and the amount of eluent was fixed at $1.5 \mathrm{~mL}$.

\section{Method validation}

Under the optimal conditions, the reliability of the proposed method was appraised by measuring various analytical parameters which included linearity, repeatability, LODs, and enrichment factors. The results

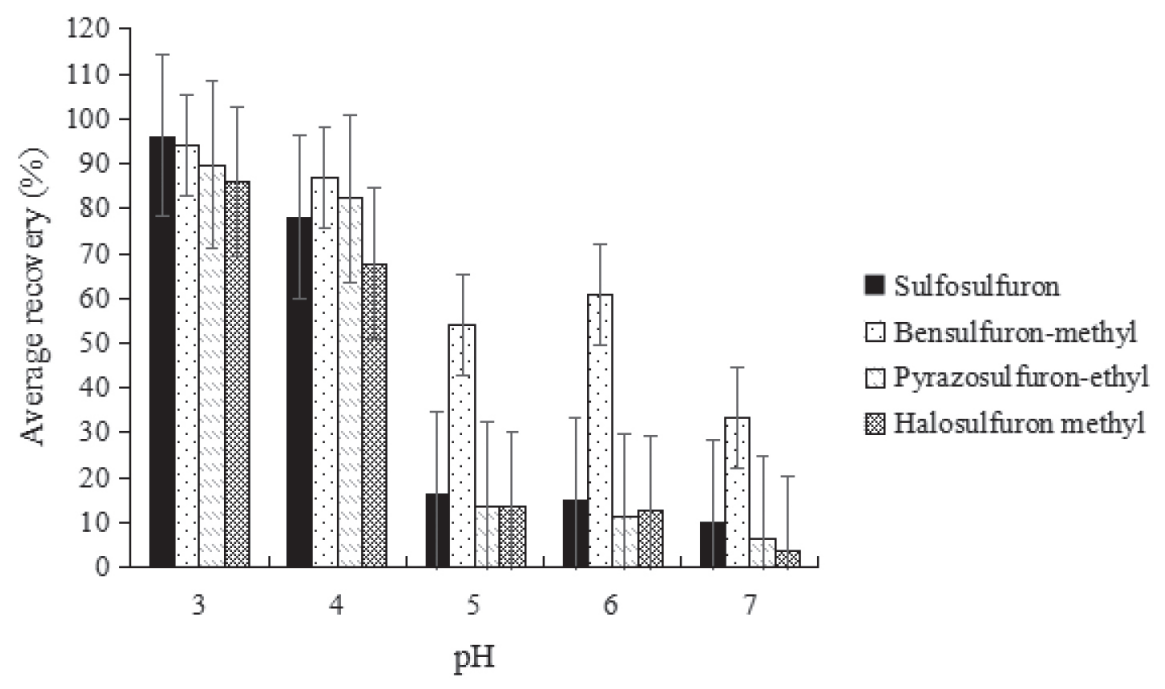

Figure 7. Effect of pH value of the solution on the extraction efficiency of SUHs. 


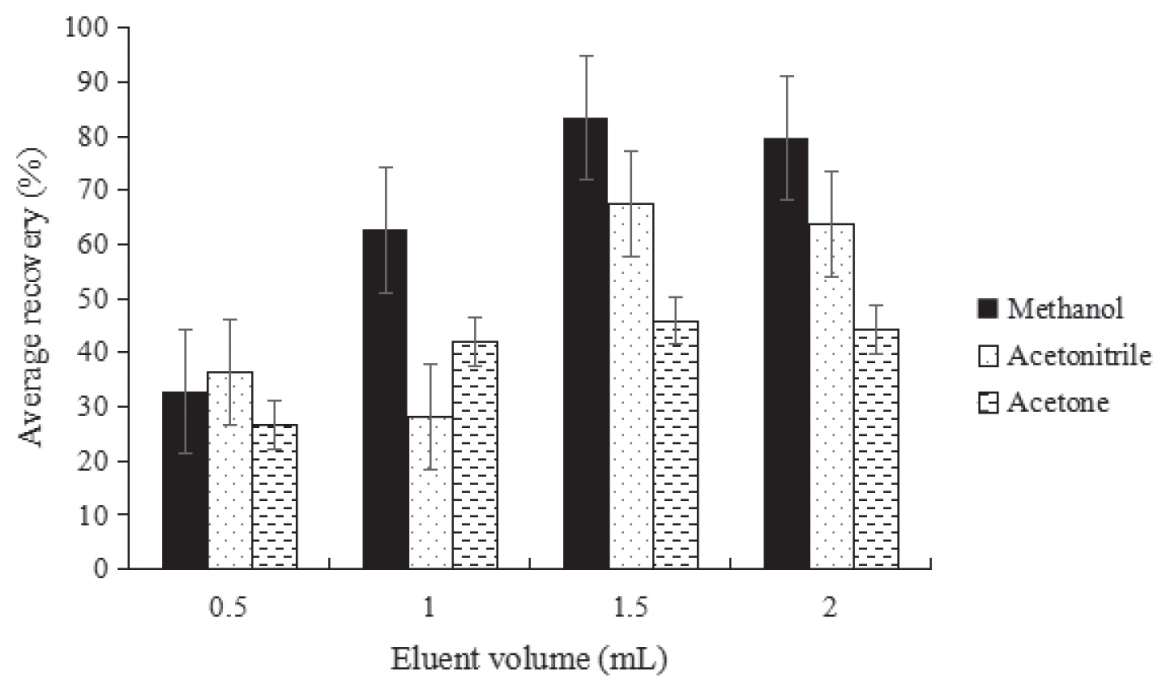

Figure 8. Effect of type and volume of desorption solvent on the extraction efficiency of sulfosulfuron.

were summarized in Table 1. A series of water solutions spiked with six SUHs at different concentrations were prepared to establish the calibration curves. Good linearities were achieved in all cases with the regression coefficients varying from 0.9927 to 0.9986 . The repeatability was achieved by spiking samples at a concentration level of $10 \mu \mathrm{g} \mathrm{L}^{-1}$, the relative standard deviations (RSDs, $\mathrm{n}=3$ ) ranged from 1.4 to $4.3 \%$, implying that the present method was precise and could meet the requirements of the analysis. The LODs, based on signal-to-noise ratio $(\mathrm{S} / \mathrm{N})$ of 3 , ranged from 0.0092 to $0.0113 \mu \mathrm{g} \mathrm{L} \mathrm{L}^{-1}$. The enrichment factors were between 495 and 615 .

\section{Real samples}

To investigate the applicability of the developed method to actual samples, the proposed method was applied to the determination of SUHs in environment and drinking water samples. The results showed that all the target analytes were not found in all the water samples. To evaluate the matrix influence on the proposed method, the environmental and drinking water samples were spiked with SUHs at concentration levels of 10 and $50 \mu \mathrm{g} \mathrm{L}{ }^{-1}$ and the data were generalized in Tables 2-3. The recoveries ranged from 61.9 to $100.1 \%$ with the RSDs $(\mathrm{n}=3)$ varying from 1.2 to $6.1 \%$ for three environmental water samples, and from 71.7 to $101.9 \%$ with the RSDs $(n=3)$ varying from 1.0 to $4.9 \%$ for three drinking water samples. From the results we can discover that matrices of experimental waters samples have no evident influence. These results demonstrated that $\mathrm{Fe}_{3} \mathrm{O}_{4} @$ PDA-DES was a promising alternative adsorbent for MSPE, and the presented MSPE-UPLC method can be applied for the isolation and determination of SUHs in water samples.

\section{Comparison of the MSPE-UPLC method with other methods}

There are a lot of researches about the methods of determining SUHs in water samples. In the present study, a comparison between the developed method and other methods was performed. Table 4 shows the LODs, the RSDs, and the volume of the organic solvent required in magnetic solid phase extraction-high performance liquid chromatography-diode array detector (MSPEHPLC-DAD), ${ }^{33}$ solid phase extraction-high performance liquid chromatography-ultraviolet (SPE-HPLC-UV), ${ }^{34}$ salting-out assisted liquid-liquid extraction-high performance liquid chromatography-diode array detector

Table 1. Correlation coefficients, linear ranges, RSDs, EF and LODs of the SUHs

\begin{tabular}{lccccc}
\hline SUH & Correlation coefficient $(\mathrm{r})$ & $\mathrm{LR} /(\mu \mathrm{g} \mathrm{L}-1)$ & $\mathrm{RSD} / \%$ & $\mathrm{EF}$ & $\mathrm{LOD} /(\mu \mathrm{g} \mathrm{L}-1)$ \\
\hline Sulfosulfuron & 0.9927 & $1-200$ & 3.1 & 586 & 0.0113 \\
Bensulfuron-methyl & 0.9928 & $1-200$ & 2.2 & 495 & 0.0095 \\
Pyrazosulfuron-methyl & 0.9938 & $1-200$ & 4.3 & 615 & 0.0095 \\
Halosulfuron-methyl & 0.9986 & $1-200$ & 1.4 & 506 & 0.0092 \\
\hline
\end{tabular}

SUH: sulfonylurea herbicide; LR: linear range; RSD: relative standard deviation; EF: enrichment factor; LOD: limit of detection. 
(SALLE-HPLC-DAD). ${ }^{35}$ It was obvious that under the optimum conditions, the LODs, RSDs and organic solvent obtained in proposed method were better than previous works. These results illustrated that MSPE-UPLC was an efficient and environmentally friendly method.

Table 2. Spiked recoveries and RSDs of five SUHs in the environmental water samples

\begin{tabular}{|c|c|c|c|c|c|c|c|}
\hline \multirow{2}{*}{ SUH } & \multirow{2}{*}{$\begin{array}{l}\text { Spiked / } \\
\left(\mu \mathrm{g} \mathrm{L}^{-1}\right)\end{array}$} & \multicolumn{2}{|c|}{ Nanhu Lake water $(\mathrm{n}=3)$} & \multicolumn{2}{|c|}{ Yezhihu Lake water $(\mathrm{n}=3)$} & \multicolumn{2}{|c|}{ Rice field water $(\mathrm{n}=3)$} \\
\hline & & Recovery / \% & $\mathrm{RSD} / \%$ & Recovery / \% & $\mathrm{RSD} / \%$ & Recovery / \% & $\mathrm{RSD} / \%$ \\
\hline \multirow{3}{*}{ Sulfosulfuron } & 0 & $\mathrm{nd}^{\mathrm{a}}$ & - & $\mathrm{nd}^{\mathrm{a}}$ & - & $\mathrm{nd}^{\mathrm{a}}$ & - \\
\hline & 10 & 73.9 & 2.3 & 94.7 & 4.1 & 86.3 & 1.2 \\
\hline & 50 & 88.8 & 4.8 & 100.1 & 3.7 & 87.6 & 2.8 \\
\hline \multirow{3}{*}{ Bensulfuron-methyl } & 0 & $\mathrm{nd}^{\mathrm{a}}$ & - & $\mathrm{nd}^{\mathrm{a}}$ & - & $\mathrm{nd}^{\mathrm{a}}$ & - \\
\hline & 10 & 76.7 & 2.9 & 94.3 & 5.0 & 84.4 & 2.9 \\
\hline & 50 & 89.2 & 2.3 & 95.3 & 1.6 & 72.6 & 1.6 \\
\hline \multirow{3}{*}{ Pyrazosulfuron-methyl } & 0 & $\mathrm{nd}^{\mathrm{a}}$ & - & $\mathrm{nd}^{\mathrm{a}}$ & - & $\mathrm{nd}^{\mathrm{a}}$ & - \\
\hline & 10 & 76.3 & 1.5 & 98.4 & 1.5 & 72.6 & 5.7 \\
\hline & 50 & 88.3 & 4.4 & 96.6 & 5.0 & 66.9 & 3.2 \\
\hline \multirow{3}{*}{ Halosulfuron-methyl } & 0 & $\mathrm{nd}^{\mathrm{a}}$ & - & $\mathrm{nd}^{\mathrm{a}}$ & - & $\mathrm{nd}^{\mathrm{a}}$ & - \\
\hline & 10 & 67.2 & 1.7 & 83.4 & 3.4 & 76.1 & 6.1 \\
\hline & 50 & 77.7 & 3.0 & 82.7 & 1.8 & 61.9 & 4.1 \\
\hline
\end{tabular}

aNot detected. SUH: sulfonylurea herbicide; RSD: relative standard deviation.

Table 3. Spiked recoveries and RSDs of five SUHs in the drinking water samples

\begin{tabular}{|c|c|c|c|c|c|c|c|}
\hline \multirow{2}{*}{ SUH } & \multirow{2}{*}{$\begin{array}{l}\text { Spiked / } \\
\left(\mu \mathrm{g} \mathrm{L}^{-1}\right)\end{array}$} & \multicolumn{2}{|c|}{ Wahaha $(\mathrm{n}=3)$} & \multicolumn{2}{|c|}{ Nongfu Spring $(\mathrm{n}=3)$} & \multicolumn{2}{|c|}{ Yibao $(\mathrm{n}=3)$} \\
\hline & & Recovery / \% & $\mathrm{RSD} / \%$ & Recovery / \% & $\mathrm{RSD} / \%$ & Recovery / \% & $\mathrm{RSD} / \%$ \\
\hline \multirow{3}{*}{ Sulfosulfuron } & 0 & $\mathrm{nd}^{\mathrm{a}}$ & - & $\mathrm{nd}^{\mathrm{a}}$ & - & $\mathrm{nd}^{\mathrm{a}}$ & - \\
\hline & 10 & 97.2 & 3.1 & 91.3 & 4.1 & 97.7 & 3.2 \\
\hline & 50 & 101.9 & 3.9 & 94.8 & 1.8 & 81.5 & 2.9 \\
\hline \multirow{3}{*}{ Bensulfuron-methyl } & 0 & $\mathrm{nd}^{\mathrm{a}}$ & - & $\mathrm{nd}^{\mathrm{a}}$ & - & $\mathrm{nd}^{\mathrm{a}}$ & - \\
\hline & 10 & 91.5 & 2.2 & 82.9 & 2.7 & 88.7 & 4.1 \\
\hline & 50 & 94.0 & 1.0 & 87.0 & 4.9 & 74.0 & 2.2 \\
\hline \multirow{3}{*}{ Pyrazosulfuron-methyl } & 0 & $\mathrm{nd}^{\mathrm{a}}$ & - & $\mathrm{nd}^{\mathrm{a}}$ & - & $\mathrm{nd}^{\mathrm{a}}$ & - \\
\hline & 10 & 97.0 & 4.3 & 71.7 & 4.9 & 86.5 & 3.7 \\
\hline & 50 & 83.7 & 4.1 & 75.8 & 4.5 & 76.2 & 3.1 \\
\hline \multirow{3}{*}{ Halosulfuron-methyl } & 0 & $\mathrm{nd}^{\mathrm{a}}$ & - & $\mathrm{nd}^{\mathrm{a}}$ & - & $\mathrm{nd}^{\mathrm{a}}$ & - \\
\hline & 10 & 90.7 & 1.4 & 72.1 & 1.7 & 80.4 & 1.6 \\
\hline & 50 & 80.0 & 1.3 & 73.9 & 3.7 & 77.1 & 4.2 \\
\hline
\end{tabular}

${ }^{a}$ Not detected. SUH: sulfonylurea herbicide; RSD: relative standard deviation.

Table 4. Comparison of the proposed method with other analytical techniques for determination of SUHs in water samples

\begin{tabular}{lccccc}
\hline Method & Organic solvent $\mathrm{used}^{\mathrm{a}} / \mathrm{mL}$ & $\mathrm{LR} /\left(\mu \mathrm{g} \mathrm{L}^{-1}\right)$ & $\mathrm{LOD} /\left(\mu \mathrm{g} \mathrm{L}^{-1}\right)$ & $\mathrm{RSD} / \%$ & $2.0-12.9$ \\
\hline MSPE-HPLC-DAD & 10.08 & $0.05-5.0$ & $0.01-0.03$ & 2.52 & 33 \\
SPE-HPLC-UV & 12.65 & $0.1-30$ & $0.1-2.0$ & $0.6-9.9$ & 34 \\
SALLE-HPLC-DAD & 4 & $1.3-100$ & $0.4-1.3$ & $1.4-4.3$ & this method \\
Presented method & 1.9 & $1-200$ & $0.009-0.011$ & 35 \\
\hline
\end{tabular}

aThis volume is related to the extraction process. LR: linear range; LOD: limit of detection; RSD: relative standard deviation; MSPE-HPLC-DAD: magnetic solid phase extraction-high performance liquid chromatography-diode array detector; SPE-HPLC-UV: solid phase extraction-high performance liquid chromatography-ultraviolet; SALLE-HPLC-DAD: salting-out assisted liquid-liquid extraction-high performance liquid chromatography-diode array detector. 


\section{Conclusions}

A simple and sensitive MSPE method coupled with UPLC has been developed. The prepared DES ( $\mathrm{ChCl} / \mathrm{EG})$ was applied to a magnetic polydopamine composite materials $\left(\mathrm{Fe}_{3} \mathrm{O}_{4} @ \mathrm{PDA}-\mathrm{DES}\right)$ and for the first time to be used as adsorbents to selectively extract SUHs during MSPE process. The results showed that the method had the advantages of low detection limit, high precision, good recoveries and high enrichment factors, which could meet the residue analysis requirements of SUHs. In the final experiment, the developed method was applied to the determination of SUHs in real samples and the acceptable results can be achieved. Considering all of its advantages, MSPE has potential to be applied in the field of pesticide residue analysis. In addition, it provides a novel choice for the pretreatment of complex matrix samples.

\section{Acknowledgments}

The present study was supported by grants from the National Key R\&D Program of China (2017YFD020030803) and National Natural Science Foundation of China (No. 21507032).

\section{References}

1. Fang, G.; Chen, J.; Wang, J.; J. Chromatogr. A 2010, 1217, 1567.

2. Yan, C.; Zhang, B.; Liu, W.; J. Chromatogr. B: Anal. Technol. Biomed. Life Sci. 2011, 879, 3484.

3. Fenoll, J.; Hellín, P.; Sabater, P.; Talanta 2012, 101, 273.

4. Wu, Q.; Wang, C.; Liu, Z.; J. Chromatogr. A 2009, 1216, 5504.

5. Tang, K.; Chen, S.; Gu, X.; Anal. Chim. Acta 2008, 614, 112.

6. Safarikova, M.; Safarik, I.; J. Magn. Magn. Mater. 1999, 194, 108.

7. Wang, D. D.; Zhao, Y.; Ou-yang, M. N.; Guo, H. M.; Yang, Z. H.; J. Chromatogr. A 2019, 1601, 53.

8. He, Z.; Liu, D.; Li, R.; Anal. Chim. Acta 2012, 747, 29.

9. Ma, J.; Jiang, L.; Wu, G.; J. Chromatogr. A 2016, 1466, 12.

10. Zhang, L.; Wu, J.; Wang, Y.; J. Am. Chem. Soc. 2012, 134, 9879.

11. Qin, Y.; Wang, M.; Sun, Z.; J. Mater. Chem. B 2013, 1, 6085.

12. Qian, Y.; Feng, Z.; Liu, W.; Chem. Soc. Rev. 2011, 40, 4244.
13. Zheng, Q.; Lin, T.; Wu, H.; Int. J. Pharm. 2014, 463, 22.

14. Lai, G.; Zhang, H.; Yong, J.; Biosens. Bioelectron. 2013, 47, 178.

15. Xia, Z.; Lin, Z.; Xiao, Y.; Biosens. Bioelectron. 2013, 47, 120.

16. Liu, R.; Sha, M.; Jiang, S.; Talanta 2014, 120, 76.

17. Wang, X.; Song, G.; Deng, C.; Talanta 2015, 132, 753.

18. Erbas, Z.; Soylak, M.; Yilmaz, E.; Dogan, M.; Microchem. J. 2019, 145, 745.

19. Abbott, A. P.; Capper, G.; Davies, D. L.; Rasheed, R. K.; Tambyrajah, V.; Chem. Commun. 2003, 9, 70.

20. Smith, E. L.; Abbott, A. P.; Ryder, K. S.; Chem. Rev. 2014, 114, 11060.

21. Abbott, A. P.; Cullis, P. M.; Gibson, M. J.; Green Chem. 2007, 9,868 .

22. Hammond, O. S.; Bowron, D. T.; Edler, K. J.; Green Chem. 2016, 18, 2736.

23. Gore, S.; Baskaran, S.; Koenig, B.; Green Chem. 2011, 13, 1009

24. Sebastián, P.; Torralba, E.; Vallés, E.; Electrochim. Acta 2015, $164,187$.

25. Gulsah, S. K.; Erkan, Y.; Mustafa, S.; J. Iran. Chem. Soc. 2018, 15, 2307.

26. Karimi, M.; Hesaraki, S.; Alizadeh, M.; Ceram. Int. 2016, 42, 2780.

27. Abdul, H. N.; Ng, M. H.; Choo, Y. M.; J. Am. Oil Chem. Soc. 2015, 92, 1709.

28. Wang, X.; Li, G.; Row, K. H.; Electrophoresis 2018, 39, 1111.

29. Tao, Z.; Zhang, X. L.; Niu, H. Y.; Appl. Catal., B 2013, 134, 26.

30. Xu, K. J.; Wang, Y. Z.; Li, Y. X.; Anal. Chim. Acta 2016, 946, 64.

31. Lawal, I. A.; Klink, M.; Ndungu, P.; Environ. Res. 2019, 179, DOI 10.1016/j.envres.2019.108837.

32. Ye, L.; Wang, Q.; Xu, J.; Shi, Z. G.; Xu, L.; J. Chromatogr. A 2012, 1244, 46.

33. Ma, J.; Jiang, L.; Wu, G.; J. Chromatogr. A. 2016, 1466, 12.

34. Shi, J.; Li, X.; Liu, C.; Shao, M.; Zhang, H.; Zhang, H.; Yu, A.; Chen, Y.; Chromatographia 2014, 77, 1283.

35. Gure, A.; Lara, F. J.; David, M. G.; Talanta 2014, 127, 51.

Submitted: November 3, 2019 Published online: March 10, 2020 